\title{
Potentially Inappropriate Medication Use in Hospitalized Elders
}

\author{
Michael B. Rothberg, MD, MPH ${ }^{1,2,3}$ \\ Penelope S. Pekow, PhD ${ }^{2,4}$ \\ Fengjuan Liu, $\mathrm{Ms}^{4}$ \\ Beatriz Korc-Grodzicki, MD, PhD ${ }^{5}$ \\ Maura J. Brennan, MD ${ }^{1,3}$ \\ Sandra Bellantonio, MD ${ }^{1,3}$ \\ Mark Heelon, PharmD ${ }^{6,7}$ \\ Peter K. Lindenauer, MD, MSc ${ }^{2,3}$ \\ ${ }^{1}$ Division of General Medicine and Geriatrics, \\ Department of Medicine, Baystate Medical Cen- \\ ter, Springfield, Massachusetts. \\ ${ }^{2}$ Division of Healthcare Quality, Baystate Medical \\ Center, Springfield, Massachusetts. \\ ${ }^{3}$ Tufts University School of Medicine, Boston, \\ Massachusetts. \\ ${ }^{4}$ School of Public Health and Health Sciences, \\ University of Massachusetts, Amherst, Massachu- \\ setts. \\ ${ }^{5}$ Department of Geriatrics and Adult Develop- \\ ment, Mount Sinai School of Medicine, New York, \\ New York. \\ ${ }^{6}$ Clinical Pharmacy Services, Baystate Medical \\ Center, Springfield, Massachusetts. \\ ${ }^{7}$ University of Connecticut School of Pharmacy, \\ Storrs, Connecticut.
}

Supported by Baystate Medical Education and Research Foundation Incubator Funds.

Dr. Rothberg is a recipient of a Doris Duke Clinical Scientist Development Award.
BACKGROUND: Prescribing of potentially harmful medications has not been well documented in hospitals.

OBJECTIVE: The objective of the study was to determine the rate of and factors associated with potentially inappropriate medication (PIM) prescribing in a large inpatient sample.

DESIGN: The study was a retrospective cohort of the period between September 1,2002 , and June 30,2005 . We used multivariable logistic regression to identify patient, physician, and hospital characteristics associated with PIM prescribing.

SETTING: The study collected data from 384 US hospitals.

PATIENTS: The sample was composed of patients aged $\geq 65$ years admitted with 1 or more of 7 common medical diagnoses.

MEASUREMENTS: The percentage of patients prescribed PIMs as defined using a modified Beers list was measured. Multivariable-adjusted odds ratios for PIM use were computed.

RESULTS: Of the 493,971 patients, $49 \%$ received at least 1 PIM, and $6 \%$ received 3 or more, most commonly promethazine, diphenhydramine, and propoxyphene. Patient, physician, and hospital characteristics were all associated with PIM use. Patients with myocardial infarction or heart failure were most likely $(61 \%$ and $52 \%$ vs. $46 \%$ for pneumonia), men ( $47 \%$ vs. $49 \%$ for women) and those in managed care plans ( $44 \%$ vs. $49 \%$ for other plans) were less likely, and patients $\geq 85$ years were least likely ( $42 \%$ vs. $53 \%$ for patients aged $65-74$ years) to receive PIMs ( $P<.0001$ for all comparisons). For high-severity PIMs, internists and hospitalists had similar prescribing rates $(33 \%)$, cardiologists had a higher rate (48\%), and geriatricians had the lowest rate $(24 \%)$. The proportion of elders receiving PIMs ranged from $34 \%$ in the Northeast to $55 \%$ in the South, and variation at the individual hospital level was extreme. At 7 hospitals, PIMs were never prescribed.

CONCLUSIONS: Wide variation in the use of PIMs is associated with hospital and physician characteristics. Care may be improved by minimizing this non-patientcentered variation. Journal of Hospital Medicine 2008;3:91-102. ( ) 2008 Society of Hospital Medicine.

KEYWORDS: drug safety, geriatric patient, pharmaceuticals, quality improvement.

M edications can be considered inappropriate when their risk outweighs their benefit. The Beers list $^{1}$ identifies medications that should be avoided in persons 65 years or older because they are ineffective or pose an unnecessarily high risk or because a safer alternative is available. Initially developed in 1991, the list has gained wide acceptance and has been updated twice. $^{2,3}$ In July 1999 it was adopted by the Centers for Medicare \& Medicaid Services (CMS) for nursing home regulation, and in 2006 the National Committee on Quality Assurance adopted a 
modified version as a Health Plan Employer Data and Information Set (HEDIS) measure of quality of care for older Americans. ${ }^{4}$

A number of studies have demonstrated that inappropriate prescribing is common in the ambulatory setting, ${ }^{5-7}$ in nursing homes, ${ }^{8,9}$ and in emergency departments ${ }^{10,11}$ and that exposure to inappropriate medications is associated with increased risk of adverse drug reactions ${ }^{12}$ and hospitalization. $^{13,14}$ Initial studies of hospitalized patients ${ }^{15-17}$ suggest that potentially inappropriate prescribing is also common among elderly inpatients and that reducing the misuse of psychotropic medications can prevent falls. ${ }^{18}$ We report on the incidence of and risk factors associated with potentially inappropriate prescribing in a large sample of hospitalized elders.

\section{METHODS \\ Patients}

We conducted a retrospective cohort study using data from 384 hospitals participating in Perspective (Premier, Inc., Charlotte, NC), a database developed for measuring quality and health care utilization. Participating hospitals represent all regions of the United States and are primarily small- to medium-sized nonteaching hospitals most of which are in urban areas. Premier collects data elements from participating hospitals via a custom data extract from hospitals' decision support system. Hospitals aggregate the data elements into their decision support systems from multiple information technology systems including billing, medical records, pharmacy, and laboratory systems. In addition to the information contained in the standard hospital discharge file, Perspective includes a date-stamped log of all billed items, including medications with dose and quantity, for individual patients.

We included patients at least 65 years old admitted between September 1, 2002, and June 30 , 2005, with a principal diagnosis of acute myocardial infarction, chronic obstructive pulmonary disease, chest pain, community-acquired pneumonia, congestive heart failure, ischemic stroke, or urinary tract infection. International Classification of Diseases, Ninth Revision (ICD-9-CM) codes were used to identify diagnoses. Patients cared for by an attending physician with a surgical specialty were excluded. The study protocol was approved by the institutional review board of Baystate Medical Center.

\section{Data Elements}

For each patient, Perspective contains fields for age, sex, race, marital status, insurance status, principal diagnosis, comorbidities, and specialty of the attending physician. Comorbidities were identified from ICD-9-CM secondary diagnosis codes and APR-DRGs using Healthcare Cost and Utilization Project Comorbidity Software, version 3.1, based on the work of Elixhauser. ${ }^{19}$ Because almost all patients had Medicare coverage, plans were classified according to managed care status. Finally, for each patient we identified all medications administered, as well as discharge status, readmission rate, total costs, and length of stay. Hospitals were categorized by region (Northeast, South, Midwest, or West), bed size, setting (urban or rural), teaching status, and whether there were geriatricians.

\section{Potentially Inappropriate Prescribing}

Using the 2002 updated Beers criteria ${ }^{3}$ for potentially inappropriate medication (PIM) use in older adults, we identified the total number of PIMs administered to each patient during his or her hospital stay. We classified each PIM as either high or low severity based on the expert consensus expressed in the 1997 update of the Beers criteria. ${ }^{2}$ The list contains 48 PIMs and an additional 20 that should be avoided in patients with certain conditions. We did not include the second category of PIMs because we did not necessarily have sufficient patient information to make this determination. In addition, some of the standard PIMs, such as laxatives, although inappropriate for chronic outpatient use, could be appropriate in the hospital setting and were excluded from this analysis. Finally, several medications were considered inappropriate only above a given threshold (eg, lorazepam $>3.0 \mathrm{mg} /$ day) or for patients without a specific diagnosis (eg, digoxin $>0.125 \mathrm{mg} /$ day for patients without atrial fibrillation). We grouped PIMs that had similar side effects into 4 categories: sedatives, anticholinergics, causing orthostasis, or causing bleeding (Fig. 1).

\section{Statistical Analysis}

Summary statistics at the patient, physician, and hospital levels were constructed using frequencies 


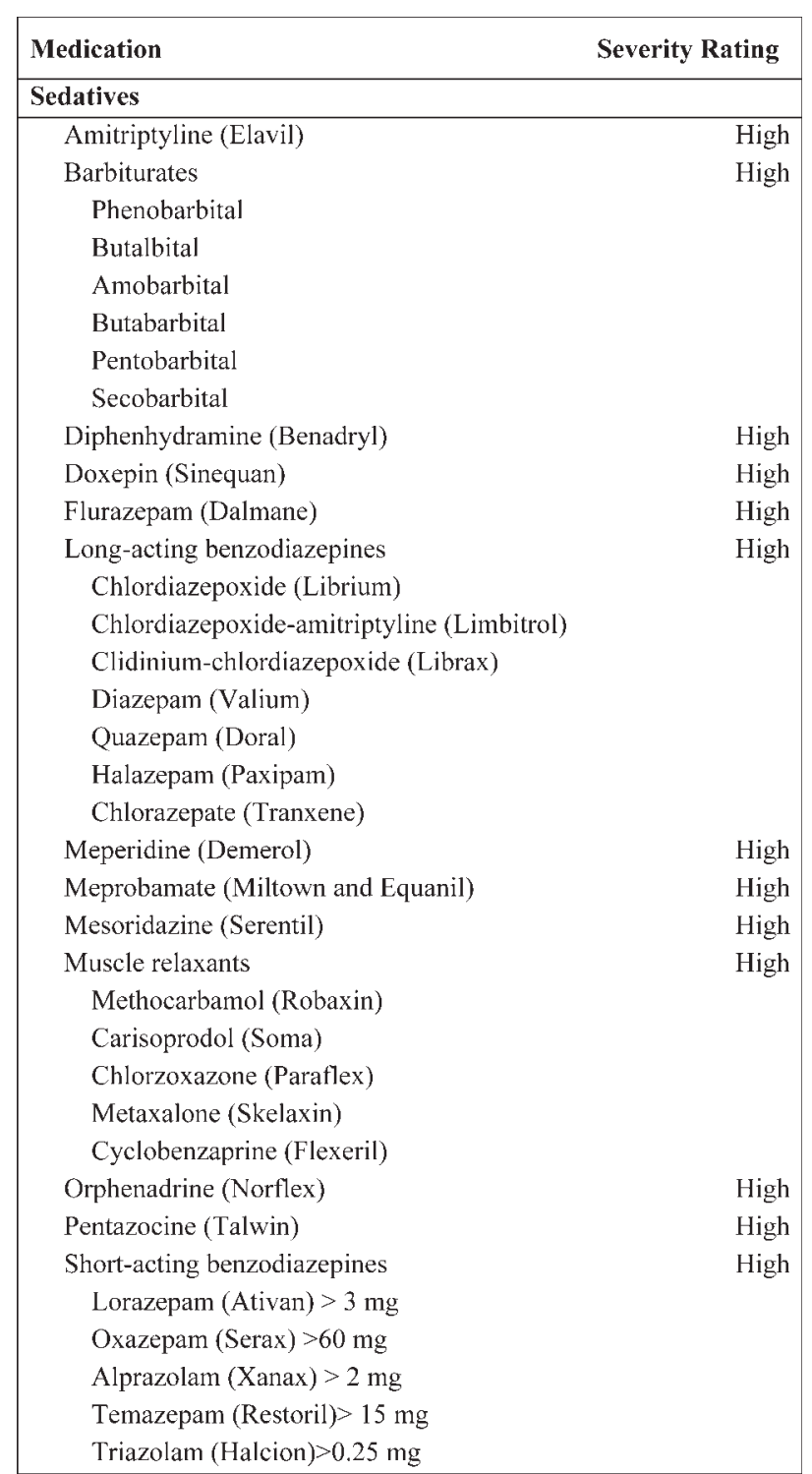

FIGURE 1. Beers list of potentially inappropriate medications modified for hospitalized patients $>65$ years old.

and proportions for categorical data and means, standard deviations, medians, interquartile ranges, and box plots for continuous-scale variables. Patients were identified as receiving a PIM if the drug was administered (above threshold dose where applicable) on at least 1 hospital day. We examined the association of each patient characteristic with use of any PIM, any high-severityrated PIM, and each side effect category using chi-square statistics. Kruskal-Wallis analysis of variance was used to examine variation in hospital use rates by each hospital characteristic, and phy-

\begin{tabular}{|lc}
\hline Thioridazine (Mellaril) & High \\
Clonidine (Catapres) & Low \\
Propoxyphene (Darvon) & Low \\
Reserpine >0.25 mg & Low \\
\hline Anticholinergic effects & High \\
\hline Amitriptyline (Elavil) & High \\
Anticholinergics and antihistamines & \\
$\quad$ Chlorpheniramine (Chlor-trimeton) & \\
Diphenhydramine (Benadryl) & \\
Hydroxyzine (Vistaril and Atarax) & \\
Cyproheptadine (Periactin) & \\
Promethazine (Phenergan) & High \\
Tripelennamine & High \\
Dexchlorpheniramine (Polaramine) & High \\
Disopyramide (Norpace and Norpace CR) & \\
Doxepin (Sinequan) & High \\
Gastrointestinal antispasmodic drugs & High \\
Dicyclomine (Bentyl) & High \\
Hyoscyamine (Levsin and Levsinex) & Low \\
Propantheline (Pro-Banthine) & \\
Belladonna alkaloids (Donnatal and others) & \\
Clidinium-Chlordiazepoxide (Librax) & \\
Muscle relaxants & High \\
Methocarbamol (Robaxin) & \\
Carisoprodol (Soma) & \\
Chlorzoxazone (Paraflex) & \\
Metaxalone (Skelaxin) & \\
Cyclobenzaprine (Flexeril) & \\
Orphenadrine (Norflex) & \\
\hline Causing orthostasis & \\
Guanadrel (Hylorel) & \\
Guanethidine (Ismelin) & \\
Short-acting nifedipine (Procardia \& Adalat) & \\
Clonidine (Catapres) & \\
Doxazosin (Cardura) & \\
artificial heart valves & Loting dipyridamote (Persantine) and \\
& \\
Reserine & \\
\hline
\end{tabular}

FIGURE 1. (continued)

sician use rates for high-severity PIMs by attending specialty. To examine whether it was feasible to avoid PIMs altogether, we compared individual hospitals as well as individual prescribers within their specialty, limiting the comparison to hospitals that contributed at least 100 patients and to physicians with at least 50 patients.

We developed a multivariable model for any high-severity medication (HS-PIM) use that included all patient, physician, and hospital characteristics except length of stay, mortality, cost, discharge status, and readmission rate. A generalized estimating equation model (SAS PROC 


\begin{tabular}{|c|c|}
\hline \multicolumn{2}{|l|}{ Causing bleeding } \\
\hline Ketorolac (Toradol) & High \\
\hline NSAIDS & High \\
\hline Naproxen (Naprosyn, Avaprox, and Aleve) & \\
\hline Oxaprozin (Daypro) & \\
\hline Piroxicam (Feldene) & \\
\hline Ticlopidine (Ticlid) & High \\
\hline \multicolumn{2}{|l|}{ Others } \\
\hline Amiodarone (Cordarone) & High \\
\hline Amphetamine & High \\
\hline Amphetamines and anorexic agents & High \\
\hline $\begin{array}{l}\text { Antispasmodics (Ditropan) except the } \\
\text { extended-release Ditropan XL }\end{array}$ & High \\
\hline $\begin{array}{l}\text { Chlordiazepoxide-amitriptyline (Limbitrol) } \\
\text { and perphenazine-amitriptyline (Triavil) }\end{array}$ & High \\
\hline Chlorpropamide (Diabinese) & High \\
\hline Daily fluoxetine (Prozac) & High \\
\hline Desiccated thyroid & High \\
\hline Indomethacin (Indocin and Indocin SR) & High \\
\hline $\begin{array}{l}\text { Methyldopa (Aldomet) and } \\
\text { methyldopa-hydrochlorothiazide (Aldoril) }\end{array}$ & High \\
\hline $\begin{array}{l}\text { Methyltestosterone (Android, Virilon and } \\
\text { testrad) }\end{array}$ & High \\
\hline Mineral oil & High \\
\hline Nitrofurantoin (Macrodantin) & High \\
\hline Trimethobenzamide (Tigan) & High \\
\hline Cimetidine (Tagamet) & Low \\
\hline Cyclandelate (Cyclospasmol) & Low \\
\hline $\begin{array}{l}\text { Digoxin (Lanoxin) }>0.125 \mathrm{mg} / \mathrm{d} \text { in patients } \\
\text { without AFIB }\end{array}$ & Low \\
\hline Ethacrynic acid (Edecrin) & Low \\
\hline $\begin{array}{l}\text { Ergot mesyloids (Hydergine) and } \\
\text { cyclandelate (cyclospasmol) }\end{array}$ & Low \\
\hline Ferrous sulfate $>325 \mathrm{mg} / \mathrm{d}$ & Low \\
\hline Isoxsurpine (Vasodilan) & Low \\
\hline \multicolumn{2}{|l|}{ Excluded Drugs } \\
\hline Long-term use of stimulant laxatives & High \\
\hline Estrogens only (oral) & Low \\
\hline
\end{tabular}

FIGURE 1. (continued)

GENMOD) with a logit link and a subcluster correlation structure was used to account for clustering at the hospital, physician, and diagnosis levels, adjusting for the clustering of primary diagnosis within physician level, nested within hospital level. Effects with $P<.10$ were retained in the model, and interaction effects were also evaluated for significance. Model fit was assessed using deviance and Pearson chi-square statistics. All analyses were performed with SAS statistical software, version 9.1 (SAS Institute, Cary, NC).

\section{RESULTS}

We identified 519,853 patients at least 65 years old during the study period; 564 were excluded because of missing data for key variables or unclear principal diagnosis. An additional 25,318 were excluded because they were cared for by an attending with a surgical specialty. A total of 493,971 patients were included in the study (Table 1). Mean age was 78 years, and $24 \%$ of patients were 85 years or older. Forty-three percent were male, $71 \%$ were white, and $39 \%$ were currently married. The most common principal diagnoses were community-acquired pneumonia, congestive heart failure, and acute myocardial infarction. The most common comorbidities were hypertension, diabetes, and chronic pulmonary disease. Medicare was the primary payer for $91 \%$ of subjects, and $13 \%$ were in managed care plans. Most patients were cared for by internists (49\%), family practitioners (18\%), or cardiologists (17\%). Only $1 \%$ of patients had a geriatrician as attending.

Just under half of all patients (49\%) received at least 1 PIM, and $6 \%$ received 3 or more (Table 2 ). Thirty-eight percent received at least 1 drug with a high severity rating (HS-PIM). The most common PIMs were promethazine, diphenhydramine, propoxyphene, clonidine, amiodarone, and lorazepam (>3 mg/day).

\section{Patient, Physician, and Hospital Factors Associated with PIMs}

Patient, physician, and hospital characteristics were all associated with use of PIMs (Table 3). In univariate analyses, older patients were less likely to receive any class of PIM, and this difference was accentuated for HS-PIMs. Women, American Indians, married people, and those not in managed care plans were slightly more likely to receive PIMs, whereas patients admitted with acute myocardial infarction or congestive heart failure were even more likely to receive PIMs $(P<.0001$ for all comparisons).

The HS-PIM prescribing varied substantially by attending specialty (Fig. 2). Internists, family practitioners, and hospitalists all had similar median rates $(33 \%)$, cardiologists had a higher median rate $(48 \%)$, and geriatricians had a lower rate (24\%). The most common PIM also differed by specialty: whereas promethazine was the most commonly prescribed drug across most specialties, nephrologists and neurologists used clonidine, pulmonologists used lorazepam, and cardiologists used diphenhydramine most often. Among the $8 \%$ of physicians who saw at least 50 
TABLE 1

Characteristics of 493,971 0lder Patients Hospitalized with 1 of 7 Common Medical Conditions

\begin{tabular}{|c|c|}
\hline Characteristic & n (\%) \\
\hline \multicolumn{2}{|l|}{ Age group } \\
\hline 65-74 years & $168,527(34 \%$ \\
\hline $75-84$ years & $206,407(42 \%$ \\
\hline $85+$ years & $119,037(24 \%$ \\
\hline \multicolumn{2}{|l|}{ Sex } \\
\hline Male & $212,358(43 \%$ \\
\hline Female & $281,613(57 \%$ \\
\hline \multicolumn{2}{|l|}{ Race } \\
\hline White & $351,331(71 \%$ \\
\hline Black & $52,429(11 \%$ \\
\hline Hispanic & $18,057(4 \%)$ \\
\hline American Indian & $1876(0 \%)$ \\
\hline Asian/Pacific Islander & $5926(1 \%)$ \\
\hline Other & $64,352(13 \%$ \\
\hline \multicolumn{2}{|l|}{ Marital status } \\
\hline Married/partner & $194,496(39 \%$ \\
\hline Widowed & $155,273(31 \%$ \\
\hline Single/separated/divorced & $75,964(15 \%$ \\
\hline Other & $68,238(14 \%$ \\
\hline \multicolumn{2}{|l|}{ Primary diagnosis } \\
\hline Pneumonia & $122,732(25 \%$ \\
\hline Heart failure & $109,071(22 \%$ \\
\hline Acute MI & $70,581(14 \%$ \\
\hline Ischemic stroke & $57,204(12 \%$ \\
\hline Chest pain & $50,404(10 \%$ \\
\hline COPD & $44,582(9 \%)$ \\
\hline Urinary tract infection & $39,397(8 \%)$ \\
\hline \multicolumn{2}{|l|}{ Comorbidities } \\
\hline Hypertension & $310,163(63 \%$ \\
\hline Diabetes & $151,755(31 \%$ \\
\hline Chronic pulmonary disease & $134,900(27 \%$ \\
\hline Fluid and electrolyte disorders & $128,703(26 \%$ \\
\hline Deficiency anemias & $92,668(19 \%$ \\
\hline Congestive heart failure & $69,201(14 \%$ \\
\hline Hypothyroidism & $68,711(14 \%$ \\
\hline Peripheral vascular disease & $47,244(10 \%$ \\
\hline Depression & $41,507(8 \%)$ \\
\hline Other neurological disorders & $40,200(8 \%)$ \\
\hline Renal failure & $38,134(8 \%)$ \\
\hline Obesity & $25,143(5 \%)$ \\
\hline \multicolumn{2}{|l|}{ Payer type } \\
\hline Not Managed care & $431,583(87 \%$ \\
\hline Managed care & $62,388(13 \%$ \\
\hline \multicolumn{2}{|l|}{ Attending physician specialty } \\
\hline Internal medicine (internist) & $241,982(49 \%$ \\
\hline Family/general medicine & $90,827(18 \%$ \\
\hline Cardiology & $83,317(17 \%$ \\
\hline Pulmonology & $21,163(4 \%)$ \\
\hline Hospitalist & $14,924(3 \%)$ \\
\hline Nephrology & $8257(2 \%)$ \\
\hline Neurology & $5800(1 \%)$ \\
\hline Geriatrics & $3099(1 \%)$ \\
\hline \multirow{2}{*}{ Other* } & $24,602(5 \%)$ \\
\hline & (continued \\
\hline
\end{tabular}

TABLE 1

(continued)

\begin{tabular}{lc}
\hline Characteristic & $\mathbf{n}(\%)$ \\
\hline Mortality & \\
$\quad$ Expired & $28,321(6 \%)$ \\
Alive & $465,650(94 \%)$ \\
Discharge status, n (\% of survivors) & \\
$\quad$ Home & $323,629(66 \%)$ \\
Nursing care & $119,468(24 \%)$ \\
Transfer/short-term hospital & $13,531(3 \%)$ \\
Hospice & $9022(2 \%)$ \\
14-Day readmission, n (\% of survivors) & \\
Yes & $35,309(8 \%)$ \\
No & $430,334(92 \%)$ \\
Length of stay (days), median (IQR) & $4(2,7)$ \\
Total cost (dollars) & $\$ 5513(\$ 3366, \$ 9902)$ \\
\hline & \\
\hline
\end{tabular}

patients, there was also great variation in each specialty (Fig. 2). Among internists and cardiologists who saw at least 50 patients, the high-severity PIM usage rate ranged from $0 \%$ to more than $90 \%$.

There was substantial variation in PIM usage among hospitals, most notably by region. The mean proportion of patients receiving PIMs ranged from $34 \%$ at hospitals in the Northeast to 55\% at hospitals in the South (Table 4). Smaller hospitals and those in urban settings had slightly lower rates, as did those that had geriatricians on staff. The teaching status of the hospital had little effect. Variation at the individual hospital level was extreme (Fig. 3). Although half of all hospitals had rates between $43 \%$ and $58 \%$, in 7 hospitals with more than 300 encounters each, PIMs were never prescribed for geriatric patients.

\section{Multivariable Model}

In a multivariable logit model that included all patient, hospital, and physician characteristics and that accounted for clustering at the hospital, physician, and diagnosis levels, several characteristics were associated with HS-PIM prescribing (Table 5). By far the most important predictor of use was hospital region. Compared with patients at hospitals in the Midwest, patients in the South (OR 1.63, 95\% CI 1.59-1.67) and West (OR 1.43, 95\% CI 1.38-1.47) were more likely and those in the Northeast were less likely (OR 0.85, 95\% CI 0.83-0.88) to receive HS-PIMs. Larger hospitals 
TABLE 2

Number and Type of Potentially Inappropriate Medications (PIMs) Prescribed

\begin{tabular}{|c|c|}
\hline & Patients, n (\%) \\
\hline \multicolumn{2}{|l|}{ Number of PIMs } \\
\hline 0 & $254,200(51 \%)$ \\
\hline 1 & $146,028(30 \%)$ \\
\hline 2 & $61,445(12 \%)$ \\
\hline 3 & $22,128(4 \%)$ \\
\hline $4+$ & $10,170(2 \%)$ \\
\hline \multicolumn{2}{|c|}{ Number of high-severity-rated PIMs } \\
\hline 0 & $304,523(62 \%)$ \\
\hline 1 & $129,588(26 \%)$ \\
\hline 2 & $43,739(9 \%)$ \\
\hline 3 & $12,213(2 \%)$ \\
\hline $4+$ & $3908(1 \%)$ \\
\hline \multicolumn{2}{|c|}{ Use of any PIM by side effect class } \\
\hline Sedatives & $156,384(32 \%)$ \\
\hline Anticholinergic effects & $109,293(22 \%)$ \\
\hline Causing orthostasis & $43,805(9 \%)$ \\
\hline Causing bleeding & $14,744(3 \%)$ \\
\hline \multicolumn{2}{|l|}{ Most commonly prescribed } \\
\hline Promethazine & $49,888(10 \%)$ \\
\hline Diphenhydramine & $45,458(9 \%)$ \\
\hline Propoxyphene & $41,786(8 \%)$ \\
\hline Clonidine & $34,765(7 \%)$ \\
\hline Amiodarone & $34,318(7 \%)$ \\
\hline Lorazepam (>3 mg/day) & $25,147(5 \%)$ \\
\hline
\end{tabular}

had higher HS-PIM rates than smaller ones, but teaching status and rural or urban setting were not associated with HS-PIM prescribing. The presence of geriatricians in a hospital was also associated with lower HS-PIM prescribing for the entire hospital.

Physician specialty was also important. Adjusting for diagnosis attenuated some of this association, but compared with internists, cardiologists (OR 1.32, 95\% CI 1.28-1.36) and pulmonologists (OR 1.10, 95\% CI 1.05-1.15) were still more likely, hospitalists (OR 0.90, 95\% CI 0.84-0.96) were less likely, and geriatricians $(0.69,95 \%$ CI 0.61-0.78) were least likely to prescribe any HSPIM.

Patient factors were also associated with HSPIM use. Compared with patients age 65-74 years, patients older than 85 years were much less likely to receive an HS-PIM (OR 0.59, CI 0.58-0.61), as to a lesser extent were nonwhites compared with whites and unmarried people compared with those who were married. Compared with patients with pneumonia, those with COPD, stroke, or chest pain were less likely and those with myocar- dial infarction and congestive heart failure were more likely to receive HS-PIMs. Patients with a secondary diagnosis of depression were also at high risk (OR 1.38, CI 1.35-1.41).

\section{DISCUSSION}

Although Americans age 65 years and older make up less than $15 \%$ of the U.S. population, they consume about one third of all prescription drugs ${ }^{20}$ and account for one third of all hospital admissions. ${ }^{21}$ Using the Beers list, numerous studies have documented high rates of potentially inappropriate prescribing for community-dwelling elderly and nursing home patients and, in some studies, an attendant risk of falling, ${ }^{22-24}$ hip fracture $^{25,26}$ hospitalization, ${ }^{13}$ or death. ${ }^{14}$ Applying these same criteria to a large sample of medical inpatients, we found that almost half received a potentially inappropriate drug, most of high severity. Moreover, the PIM prescribing rate varied substantially by region, hospital, and attending physician specialty. Although the use of PIMs was associated with patient age, comorbidities, and primary diagnosis, these patient factors explained only a small portion of the variation in prescribing practices across groups of physicians and hospitals.

Using consensus criteria, Beers originally found that $40 \%$ of the residents in 12 nursing homes received at least $1 \mathrm{PIM}^{8}$ and studies of community-dwelling elderly demonstrated rates of $21 \%$ to $37 \%$, with little change over time. ${ }^{6,27,28}$ Several small studies have examined inpatient prescribing. ${ }^{16,17,29,30}$ The largest ${ }^{17}$ found that only $15 \%$ of elderly Italian inpatients received a PIM. Our finding, that $49 \%$ of inpatients had received at least 1 PIM, may partially reflect the high prevalence of use among elderly US patients in nursing homes and the community.

Regional variation has been demonstrated for ambulatory patients in the $\mathrm{US}^{6}$ and Europe. ${ }^{31}$ Zhan et al. found slightly higher rates of PIM use in the Midwest and the South (23\%) than in the Northeast and the West (19\%). Variation in Europe was greater, with $41 \%$ of patients in the Czech Republic versus $5.8 \%$ of patients in Denmark receiving at least 1 PIM. We found that region was the strongest predictor of in-hospital HS-PIM use, with patients in the South most likely and patients in the Northeast least likely to receive HS-PIMs. This variation persisted even after adjusting for differences in other patient and hospital factors, 


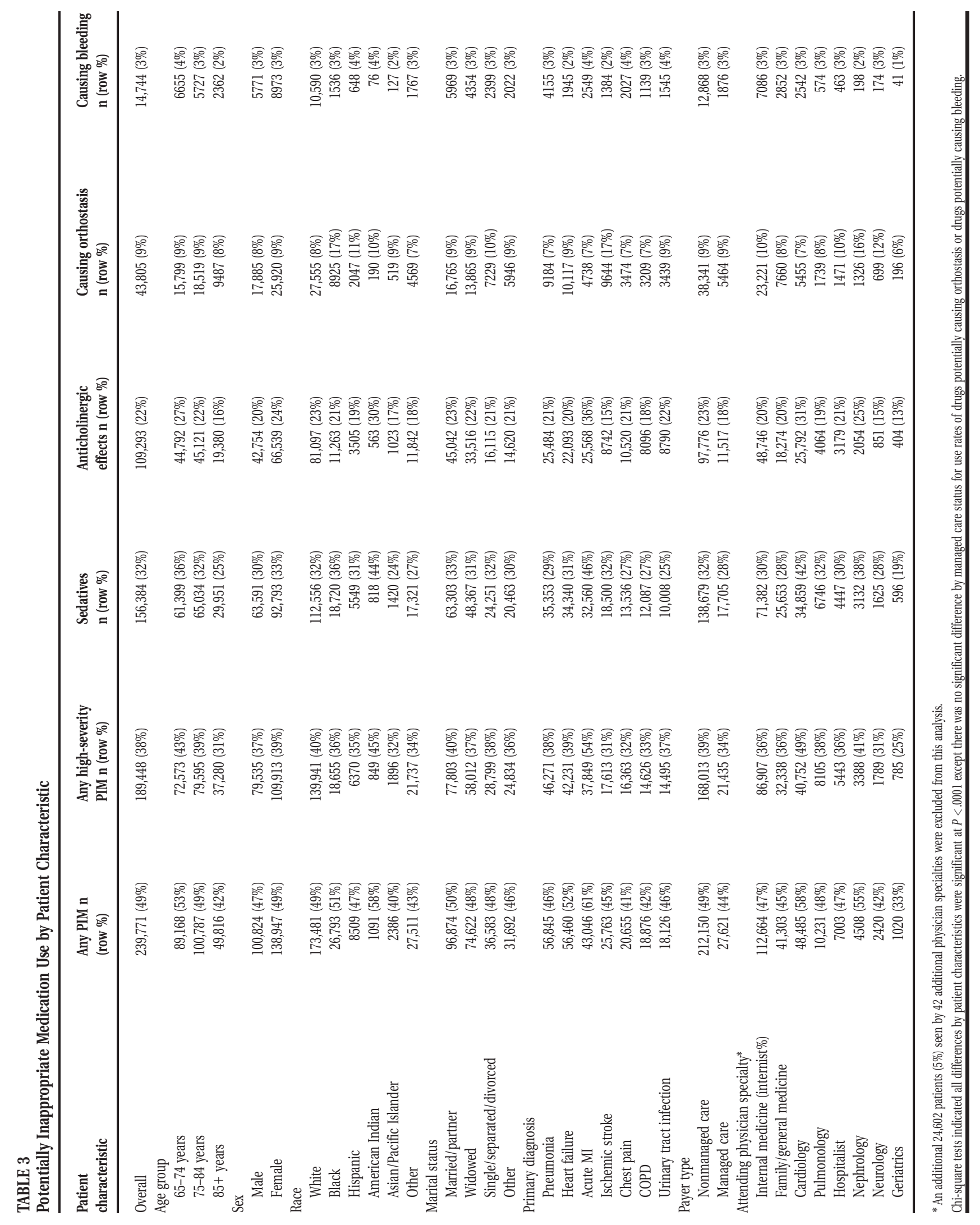




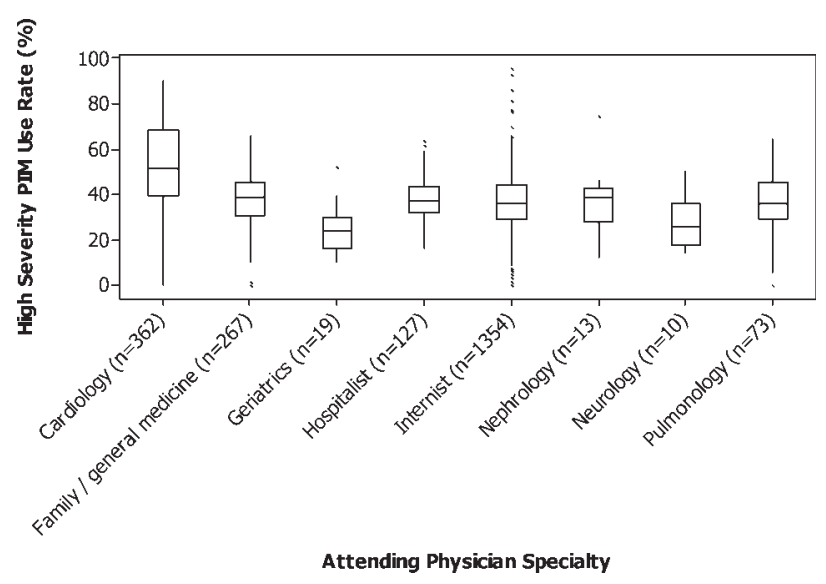

FIGURE 2. Distribution of physician prescribing rates for high-severityrated PIM by specialty for physicians treating at least 50 hospitalized patients during the study period ( $\mathrm{N}$, number of physicians in each specialty). The line in the middle of each box represents the median use rate across physicians, and the box extends to the interquartile range (IQR). The lines emerging from the box extend to the adjacent values. The upper adjacent value is defined as the largest data point less than or equal to the 75th percentile plus 1.5 times the IQR; the lower adjacent value is defined as the smallest data point greater than or equal to the 25th percentile minus 1.5 IQR. Observed points more extreme than the adjacent values are individually plotted.

suggesting that local custom played a large role in the decision to prescribe HS-PIMs. Moreover, because outpatient rates are more uniform, these large differences seem limited to inpatient practice.

Patient factors have also been examined. Advanced age was associated with decreased PIM use in some studies ${ }^{17,28,31}$ but not in others. ${ }^{6,27} \mathrm{We}$ found increasing age to be strongly associated with decreased PIM use, suggesting that in the hospital, at least, doctors take care to avoid prescribing certain drugs to the frail elderly. Women appear to be consistently at higher risk than men, ${ }^{6,27,28,31}$ and white patients are more at risk than those of other races. ${ }^{6}$ Our finding that certain diagnoses were associated with higher or lower rates has not been reported previously. The lower rates associated with stroke and COPD suggest that prescribers were aware that these patients were at increased risk of delirium and respiratory depression. The higher rates associated with myocardial infarction may have to do with the use of standardized order sets (eg, cath lab orders) that do not consider the age of the patient going for the procedure.
Admission to a geriatric service ${ }^{32}$ and intervention by a clinical pharmacist ${ }^{33}$ have been shown to decrease PIM prescribing at discharge. We noted that patients cared for by a geriatrician had the lowest rates of PIM prescribing during hospitalization as well and that hospitals with geriatricians had lower rates overall, possibly demonstrating that geriatricians had a "ripple effect" on their colleagues. Hospitalists also had lower rates than internists, supporting the notion that hospitalists provide higher-quality inpatient care.

Our study had some important limitations. First, we only had access to inpatient administrative records. Thus, we could not identify which medications were continued from home and which were begun in the hospital, nor could we know the indications for which specific drugs were prescribed or who prescribed them. Based on published outpatient rates, however, we could assume that many of the drugs were started in the hospital and that others could have been discontinued but were not. Second, the Beers list was developed by the modified Delphi method; there was little empirical evidence of the danger of specific drugs, although some classes, such as benzodiazepines, opiates and digoxin, have been associated with inpatient falls. ${ }^{18,34-36}$ Furthermore, our administrative database did not allow us to balance the risks and benefits for particular patients; hence, the medications were only "potentially inappropriate," and our study did not address the consequences of such prescribing. Although some of these drugs may be appropriate under certain circumstances, it is unlikely that these circumstances would vary by $60 \%$ across geographic regions or that internists would encounter these circumstances more often than do hospitalists. Thus, although we could not identify specific patients who received inappropriate medications, we did identify certain hospitals and even whole regions of the country in which the rate of inappropriate prescribing was high. Third, the Beers list, which was developed for outpatient use, may be less relevant in the inpatient setting. However, given that inpatients have more organ dysfunction and are at higher risk of delirium and falls, it may actually be more applicable to hospitalized patients. We similarly did not distinguish between single and multiple doses because the Beers list does not make such a distinction, and there is no empirical evidence that a single dose is safe. Indeed, patients are often at highest risk of 
TABLE 4

Percentage of Patients Prescribed Potentially Inappropriate Medication (PIM) by Hospital Characteristic

\begin{tabular}{|c|c|c|c|c|c|c|c|c|}
\hline & $\begin{array}{l}\text { Hospitals } \\
\text { Total = } 384 \\
\text { n (\%) }\end{array}$ & $\begin{array}{l}\text { Patients } \\
\mathrm{N}=49,3971 \\
\text { n (\%) }\end{array}$ & $\begin{array}{l}\text { Any PIM } \\
\text { Mean }=48.2 \\
\text { Mean }(\mathrm{SD})\end{array}$ & $\begin{array}{l}\text { Any high-severity } \\
\text { PIM Mean }=38.7 \\
\text { Mean (SD) }\end{array}$ & $\begin{array}{l}\text { Sedatives } \\
\text { Mean = } 30.2 \\
\text { Mean (SD) }\end{array}$ & $\begin{array}{l}\text { Anticholinergic } \\
\text { effects Mean = } 21.5 \\
\text { Mean (SD) }\end{array}$ & $\begin{array}{l}\text { Causing orthostasis } \\
\text { Mean = 8.5 } \\
\text { Mean (SD) }\end{array}$ & $\begin{array}{l}\text { Causing bleeding } \\
\text { Mean = 3.1 } \\
\text { Mean (SD) }\end{array}$ \\
\hline Hospital region & & & $* * *$ & $* * *$ & $* * *$ & $* * *$ & $* * *$ & $* *$ \\
\hline Midwest & $76(20 \%)$ & $95,791(19 \%)$ & 38.8 (19.7) & 30.0 (16.4) & $24.3(13.8)$ & $15.1(9.9)$ & $6.9(6.3)$ & $3.1(2.3)$ \\
\hline Northeast & 47 (12\%) & $79,138(16 \%)$ & $34.1(12.6)$ & $26.2(11.2)$ & $19.0(9.2)$ & $13.5(8.1)$ & $4.9(2.3)$ & $2.1(1.6)$ \\
\hline South & $199(52 \%)$ & $260,870(53 \%)$ & $54.5(10.1)$ & $42.7(9.6)$ & $36.0(10.8)$ & $26.4(8.6)$ & $10.4(4.6)$ & $3.6(2.5)$ \\
\hline West & $62(16 \%)$ & $58,172(12 \%)$ & $45.8(8.1)$ & $37.4(7.1)$ & $27.3(7.7)$ & $19.5(5.7)$ & $7.4(4.8)$ & $2.7(1.3)$ \\
\hline \multicolumn{9}{|l|}{ Teaching status } \\
\hline Nonteaching & $297(77 \%)$ & $324,948(66 \%)$ & 47.3 (14.6) & 36.9 (12.3) & $29.8(12.0)$ & $21.3(9.9)$ & $8.7(5.4)$ & $3.3(2.4)$ \\
\hline Teaching & $87(23 \%)$ & $169,023(34 \%)$ & $48.2(16.0)$ & $38.8(14.2)$ & $31.6(14.5)$ & $22.1(10.2)$ & $7.8(4.4)$ & $2.7(1.5)$ \\
\hline Staffed beds & & & & $*$ & $* *$ & & & \\
\hline 22-200 & $143(37 \%)$ & $80,741(16 \%)$ & 45.5 (16.9) & $35.2(14.6)$ & $27.5(14.0)$ & $20.1(10.3)$ & $8.0(6.2)$ & $3.5(3.1)$ \\
\hline $200-400$ & $137(36 \%)$ & $177,286(36 \%)$ & $47.7(14.2)$ & $37.8(12.0)$ & 30.5 (11.6) & $22.0(10.0)$ & $8.4(4.7)$ & $3.0(1.6)$ \\
\hline $400+$ & $104(27 \%)$ & $235944(48 \%)$ & $50.1(12.4)$ & $39.6(10.6)$ & 33.5 (10.9) & $22.7(9.3)$ & $9.3(4.2)$ & $2.9(1.4)$ \\
\hline Population serviced & & & & & & $*$ & $*$ & $* *$ \\
\hline Rural & $119(31 \%)$ & $102,799(21 \%)$ & $48.4(13.0)$ & $38.3(10.6)$ & $29.2(11.0)$ & $23.2(9.3)$ & $7.5(4.0)$ & $3.7(3.0)$ \\
\hline Urban & $265(69 \%)$ & $391,172(79 \%)$ & 47.1 (15.7) & 36.9 (13.7) & $30.6(13.2)$ & $20.7(10.2)$ & $9.0(5.6)$ & $2.9(1.8)$ \\
\hline \multicolumn{9}{|l|}{ Geriatrician presence } \\
\hline No & $340(89 \%)$ & $409,281(83 \%)$ & 47.7 (15.3) & $37.6(13.0)$ & 30.3 (12.8) & $21.7(10.0)$ & $8.4(5.3)$ & $3.2(2.3)$ \\
\hline Yes & $44(11 \%)$ & $84,690(17 \%)$ & 45.8 (11.4) & 35.5 (10.6) & $29.4(10.8)$ & $19.6(9.4)$ & $9.3(4.3)$ & $2.9(1.6)$ \\
\hline
\end{tabular}

Note: $P$ values from analysis of variance of hospital use rates for each hospital characteristic.

${ }^{*} P<.05,{ }^{* *} P<.001,{ }^{* * *} P<.0001$.

falls immediately after initiation of therapy. ${ }^{37-39}$ We did, however, exclude drugs such as laxatives, which may be appropriate for brief inpatient use but not for chronic use.

Our study also had a number of strengths. The large sample size, representing approximately $5 \%$ of annual inpatient admissions in the US over 2 years, offered an instructive look at the recent prescribing patterns of thousands of US physicians. We were able to identify many patient, physician, and hospital factors associated with PIM prescribing that have not previously been reported. Some of these factors, such as advanced age and comorbid diagnoses, suggest that physicians do tailor their treatment to individual patients. Nevertheless, patient factors accounted for only a small portion of the variation in prescribing. The largest variation, associated with regional, hospital, and physician factors, highlights the opportunity for improvement.

At the same time, our findings are encouraging for 2 reasons. First, most inappropriate prescribing involved only a handful of medications, so small changes in prescribing patterns could have a tre-

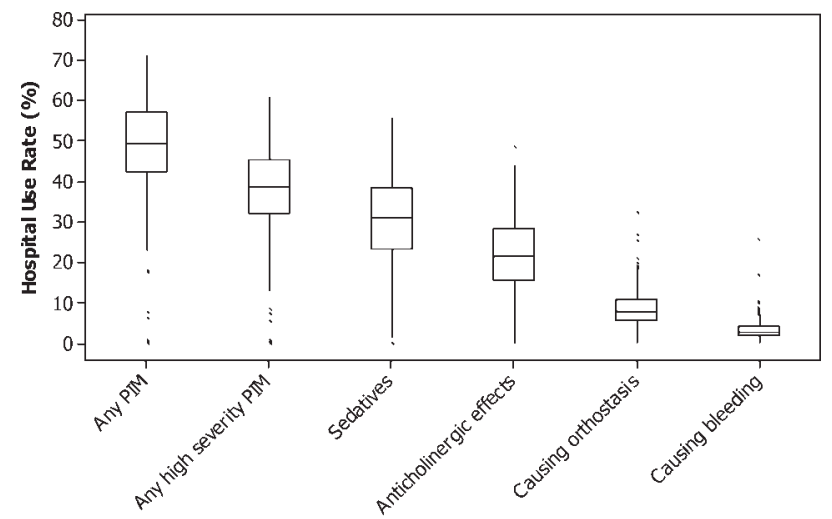

FIGURE 3. Distribution of hospital use rates for each category of PIM among hospitals with at least 100 eligible patients during the study period. Thirteen hospitals $(3 \%)$ and 324 patients $(<0.1 \%)$ were excluded. For interpretation of the box plots, see Figure 2.

mendous impact. Second, observing the practice of individual physicians and hospitals reveals what is possible. We found that in most specialties there were physicians who rarely or never used PIMs. We also found 7 hospitals, each with at least 300 cases, where no PIMs were ever prescribed. 
TABLE 5

Adjusted Odds Ratio Estimates for High-Severity PIM Use

\begin{tabular}{|c|c|c|c|}
\hline \multirow{2}{*}{$\begin{array}{l}\text { Effect (reference) } \\
\text { Age }\end{array}$} & \multirow[t]{2}{*}{ Odds ratio } & \multicolumn{2}{|c|}{$\begin{array}{l}95 \% \text { Confidence } \\
\text { limits }\end{array}$} \\
\hline & & & \\
\hline 65-74 years & 1.00 & - & - \\
\hline 75-84 years & 0.83 & 0.82 & 0.84 \\
\hline $85+$ years & 0.59 & 0.58 & 0.61 \\
\hline \multicolumn{4}{|l|}{ Sex } \\
\hline Female & 1.00 & - & - \\
\hline Male & 0.85 & 0.83 & 0.86 \\
\hline \multicolumn{4}{|l|}{ Race } \\
\hline White & 1.00 & - & - \\
\hline Black & 0.78 & 0.76 & 0.80 \\
\hline Hispanic & 0.84 & 0.81 & 0.87 \\
\hline American Indian & 0.97 & 0.88 & 1.07 \\
\hline Asian/Pacific Islander & 0.74 & 0.70 & 0.79 \\
\hline Other & 0.94 & 0.92 & 0.97 \\
\hline \multicolumn{4}{|l|}{ Marital Status } \\
\hline Married/partner & 1.00 & - & - \\
\hline Single/separated/divorced & 0.96 & 0.94 & 0.98 \\
\hline Widowed & 0.96 & 0.95 & 0.98 \\
\hline Other & 0.93 & 0.90 & 0.95 \\
\hline \multicolumn{4}{|l|}{ Primary diagnosis } \\
\hline Pneumonia & 1.00 & - & - \\
\hline COPD & 0.83 & 0.81 & 0.85 \\
\hline Heart failure & 1.14 & 1.12 & 1.16 \\
\hline Ischemic stroke & 0.84 & 0.82 & 0.86 \\
\hline Acute MI & 1.95 & 1.90 & 2.01 \\
\hline Urinary tract infection & 1.06 & 1.03 & 1.09 \\
\hline Chest pain & 0.87 & 0.84 & 0.89 \\
\hline \multicolumn{4}{|l|}{ Comorbidities (yes or no) } \\
\hline Hypertension & 0.98 & 0.97 & 0.99 \\
\hline Diabetes & 0.98 & 0.97 & 1.00 \\
\hline Chronic lung disease & 1.11 & 1.10 & 1.13 \\
\hline Fluid and electrolyte disorders & 1.26 & 1.24 & 1.27 \\
\hline Anemia deficiencies & 1.17 & 1.15 & 1.18 \\
\hline Congestive heart failure & 1.34 & 1.32 & 1.37 \\
\hline Hypothyroidism & 1.13 & 1.11 & 1.15 \\
\hline Peripheral vascular disease & 1.09 & 1.06 & 1.11 \\
\hline Depression & 1.38 & 1.35 & 1.41 \\
\hline Neurological disorders & 0.89 & 0.87 & 0.91 \\
\hline Renal failure & 1.23 & 1.20 & 1.26 \\
\hline Obesity & 1.11 & 1.08 & 1.14 \\
\hline \multicolumn{4}{|l|}{ Payer type } \\
\hline Managed care & 1.00 & - & - \\
\hline Not managed care & 1.04 & 1.02 & 1.06 \\
\hline \multicolumn{4}{|l|}{ Attending physician specialty } \\
\hline Internal medicine & 1.00 & - & - \\
\hline Cardiology & 1.32 & 1.28 & 1.36 \\
\hline Family/general medicine & 0.99 & 0.97 & 1.01 \\
\hline Geriatrics & 0.69 & 0.61 & 0.78 \\
\hline Hospitalist & 0.90 & 0.84 & 0.96 \\
\hline Nephrology & 1.02 & 0.96 & 1.08 \\
\hline Neurology & 0.93 & 0.86 & 1.00 \\
\hline Pulmonology & 1.10 & 1.05 & 1.15 \\
\hline \multicolumn{4}{|l|}{ Setting } \\
\hline Rural & 1.00 & - & - \\
\hline \multirow[t]{2}{*}{ Urban } & 1.02 & 1.00 & 1.05 \\
\hline & & \multicolumn{2}{|c|}{ (continued) } \\
\hline
\end{tabular}

TABLE 5

(continued)

\begin{tabular}{|c|c|c|c|}
\hline Effect (reference) & Odds ratio & $\begin{array}{l}95 \% \\
\text { limits }\end{array}$ & \\
\hline \multicolumn{4}{|l|}{ Teaching status } \\
\hline Nonteaching & 1.00 & - & - \\
\hline Teaching & 1.01 & 0.98 & 1.03 \\
\hline \multicolumn{4}{|l|}{ Number of beds } \\
\hline $22-200$ & 1.00 & - & - \\
\hline $200-400$ & 1.08 & 1.05 & 1.11 \\
\hline $400+$ & 1.12 & 1.09 & 1.16 \\
\hline \multicolumn{4}{|l|}{ Region } \\
\hline Midwest & 1.00 & - & - \\
\hline Northeast & 0.85 & 0.83 & 0.88 \\
\hline South & 1.63 & 1.59 & 1.67 \\
\hline West & 1.43 & 1.38 & 1.47 \\
\hline \multicolumn{4}{|c|}{ Geriatrician presence } \\
\hline No & 1.00 & - & - \\
\hline Yes & 0.93 & 0.90 & 0.95 \\
\hline
\end{tabular}

Where should hospitals focus their efforts to prevent inappropriate prescribing? Our data highlight the complexity of the problem, which seems daunting. PIM prescribing is spread across all specialties, including geriatrics, and although cardiologists had the highest rate of prescribing, internists, who were more numerous, accounted for a much higher overall number of potentially inappropriate prescriptions. It would be instructive to study the 7 hospitals where PIMs were never prescribed or to interview those physicians who never prescribed PIMs, but the anonymous nature of our data would not allow for this. However, our data do suggest some directions. First, hospitals should become aware of their own rates of PIM use because measurement is the first step in quality improvement. Next, hospitals should focus efforts on reducing the use of the most common drugs. Eliminating just 3 drugspromethazine, diphenhydramine, and propoxyphene-would reduce the use of PIMs in $24 \%$ of elderly patients. Enlisting hospital pharmacists and electronic health records and reviewing standard order sets for elderly patients are potentially effective strategies. Finally, increasing the presence of geriatricians and hospitalists would be expected to have a modest impact.

In a representative sample of elderly inpatients, we found that almost half received a potentially inappropriate medication and that the rate of inappropriate prescribing varied widely among doctors and hospitals. Additional research is 
needed to distinguish which of the Beers drugs are most harmful and which patients are at highest risk. Research should also focus on understanding differences in prescribing patterns, perhaps by studying the outliers at both ends of the quality spectrum, and on techniques to minimize non-patient-centered variation.

Address for correspondence and reprint requests: Michael Rothberg, MD, MPH, Division of General Medicine and Geriatrics, Baystate Medical Center, 759 Chestnut Street, Springfield, MA 01199; Fax: (413) 794-4147; E-mail: Michael.Rothberg@bhs.org

Received 24 April 2007; revision received 3 September 2007; accepted 4 September 2007.

\section{REFERENCES}

1. Beers MH, Ouslander JG, Rollingher I, Reuben DB, Brooks J, Beck JC. Explicit criteria for determining inappropriate medication use in nursing home residents. UCLA Division of Geriatric Medicine. Arch Intern Med. 1991;151:1825-1832.

2. Beers MH. Explicit criteria for determining potentially inappropriate medication use by the elderly. An update. Arch Intern Med. 1997;157:1531-1536.

3. Fick DM, Cooper JW, Wade WE, Waller JL, Maclean JR, Beers MH. Updating the Beers criteria for potentially inappropriate medication use in older adults: results of a US consensus panel of experts. Arch Intern Med. 2003;163: 2716-2724.

4. National Committee on Quality Assurance. Drugs to be Avoided in the Elderly. Available at: http://www.ncqa.org/ Programs/HEDIS/2006/Volume2/NDC/DAE_06.xls. Accessed November 20, 2006.

5. Curtis LH, Ostbye T, Sendersky V, et al. Inappropriate prescribing for elderly Americans in a large outpatient population. Arch Intern Med. 2004;164:1621-1625.

6. Zhan C, Sangl J, Bierman AS, et al. Potentially inappropriate medication use in the community-dwelling elderly: findings from the 1996 Medical Expenditure Panel Survey. JAMA. 2001;286:2823-2829.

7. Mort JR, Aparasu RR. Prescribing potentially inappropriate psychotropic medications to the ambulatory elderly. Arch Intern Med. 2000;160:2825-2831.

8. Beers MH, Ouslander JG, Fingold SF, et al. Inappropriate medication prescribing in skilled-nursing facilities. Ann Intern Med. 1992;117:684-689.

9. Perri M, 3rd, Menon AM, Deshpande AD, et al. Adverse outcomes associated with inappropriate drug use in nursing homes. Ann Pharmacother. 2005;39:405-411.

10. Caterino JM, Emond JA, Camargo CA. Inappropriate medication administration to the acutely ill elderly: a nationwide emergency department study, 1992-2000. J Am Geriatr Soc. 2004;52:1847-1855.

11. Chin MH, Wang LC, Jin L, et al. Appropriateness of medication selection for older persons in an urban academic emergency department. Acad Emerg Med. 1999;6:1232-1242.

12. Chang CM, Liu PY, Yang YH, Yang YC, Wu CF, Lu FH. Use of the Beers criteria to predict adverse drug reactions among first-visit elderly outpatients. Pharmacotherapy. 2005; 25:831-838.
13. Klarin I, Wimo A, Fastbom J. The association of inappropriate drug use with hospitalisation and mortality: a population-based study of the very old. Drugs Aging. 2005; 22(1):69-82.

14. Lau DT, Kasper JD, Potter DE, Lyles A, Bennett RG. Hospitalization and death associated with potentially inappropriate medication prescriptions among elderly nursing home residents. Arch Intern Med. 2005;165(1):68-74.

15. Edwards RF, Harrison TM, Davis SM. Potentially inappropriate prescribing for geriatric inpatients: an acute care of the elderly unit compared to a general medicine service. Consult Pharm. 2003;18(1):37-42, 47-39.

16. Hanlon JT, Artz MB, Pieper CF, et al. Inappropriate medication use among frail elderly inpatients. Ann Pharmacother. 2004;38(1):9-14.

17. Onder G, Landi F, Cesari M, Gambassi G, Carbonin P, Bernabei R. Inappropriate medication use among hospitalized older adults in Italy: results from the Italian Group of Pharmacoepidemiology in the Elderly. Eur J Clin Pharmacol. 2003;59(2):157-162.

18. Peterson JF, Kuperman GJ, Shek C, Patel M, Avorn J, Bates DW. Guided prescription of psychotropic medications for geriatric inpatients. Arch Intern Med. 2005;165:802-807.

19. Elixhauser A, Steiner C, Harris DR, Coffey RM. Comorbidity measures for use with administrative data. Med Care. 1998;36(1):8-27.

20. Soumerai SB, Ross-Degnan D. Inadequate prescriptiondrug coverage for Medicare enrollees-a call to action. $N$ Engl J Med. 1999;340:722-728.

21. National and regional estimates on hospital use for all patients from the HCUP Nationwide Inpatient Sample (NIS). Agency for Healthcare Research and Quality (AHRQ). Available at: http://hcupnet.ahrq.gov/HCUPnet.jsp. Accessed October 12, 2006.

22. French DD, Campbell R, Spehar A, Cunningham F, Bulat T, Luther SL. Drugs and falls in community-dwelling older people: a national veterans study. Clin Ther. 2006;28: 619-630.

23. Landi F, Onder G, Cesari M, Barillaro C, Russo A, Bernabei R. Psychotropic medications and risk for falls among community-dwelling frail older people: an observational study. J Gerontol A Biol Sci Med Sci. 2005;60:622-626.

24. Leipzig RM, Cumming RG, Tinetti ME. Drugs and falls in older people: a systematic review and meta-analysis: I. Psychotropic drugs. J Am Geriatr Soc. 1999;47(1):30-39.

25. Kamal-Bahl SJ, Stuart BC, Beers MH. Propoxyphene use and risk for hip fractures in older adults. Am J Geriatr Pharmacother. 2006;4:219-226.

26. Ensrud KE, Blackwell T, Mangione CM, et al. Central nervous system active medications and risk for fractures in older women. Arch Intern Med. 2003;163:949-957.

27. Simon SR, Chan KA, Soumerai SB, et al. Potentially inappropriate medication use by elderly persons in U.S. Health Maintenance Organizations, 2000-2001. J Am Geriatr Soc. 2005;53:227-232.

28. Goulding MR. Inappropriate medication prescribing for elderly ambulatory care patients. Arch Intern Med. 2004 2004;164:305-312.

29. Passarelli MC, Jacob-Filho W, Figueras A. Adverse drug reactions in an elderly hospitalised population: inappropriate prescription is a leading cause. Drugs Aging. 2005;22: 767-777. 
30. Raivio MM, Laurila JV, Strandberg TE, Tilvis RS, Pitkala KH. Use of inappropriate medications and their prognostic significance among in-hospital and nursing home patients with and without dementia in Finland. Drugs Aging. 2006;23:333-343.

31. Fialova D, Topinkova E, Gambassi G, et al. Potentially inappropriate medication use among elderly home care patients in Europe. JAMA. 2005;293:1348-1358.

32. Laroche ML, Charmes JP, Nouaille Y, Fourrier A, Merle L. Impact of hospitalisation in an acute medical geriatric unit on potentially inappropriate medication use. Drugs Aging. 2006;23(1):49-59.

33. Brown BK, Earnhart J. Pharmacists and their effectiveness in ensuring the appropriateness of the chronic medication regimens of geriatric inpatients. Consult Pharm. 2004;19: 432-436.

34. Passaro A, Volpato S, Romagnoni F, Manzoli N, Zuliani G, Fellin R. Benzodiazepines with different half-life and falling in a hospitalized population: the GIFA study. Gruppo Ita- liano di Farmacovigilanza nell'Anziano. J Clin Epidemiol. 2000;53:1222-1229.

35. Gales BJ, Menard SM. Relationship between the administration of selected medications and falls in hospitalized elderly patients. Ann Pharmacother. 1995;29:354-358.

36. Mendelson WB. The use of sedative/hypnotic medication and its correlation with falling down in the hospital. Sleep. 1996;19:698-701.

37. Wagner AK, Zhang F, Soumerai SB, et al. Benzodiazepine use and hip fractures in the elderly: who is at greatest risk? Arch Intern Med. 2004;164:1567-1572.

38. Wang PS, Bohn RL, Glynn RJ, Mogun H, Avorn J. Hazardous benzodiazepine regimens in the elderly: effects of halflife, dosage, and duration on risk of hip fracture. Am J Psychiatry. 2001;158:892-898.

39. Tamblyn R, Abrahamowicz M, du Berger R, McLeod P, Bartlett G. A 5-year prospective assessment of the risk associated with individual benzodiazepines and doses in new elderly users. J Am Geriatr Soc. 2005;53:233-241. 